Article

\title{
On-Demand Micro-Power Generation from an Origami-Inspired Paper Biobattery Stack
}

\author{
Maedeh Mohammadifar and Seokheun Choi * \\ Bioelectronics \& Microsystems Laboratory, Department of Electrical \& Computer Engineering, State University \\ of New York-Binghamton, Binghamton, NY 13902, USA; mmoham11@binghamton.edu \\ * Correspondence: sechoi@binghamton.edu
}

Received: 9 February 2018; Accepted: 16 March 2018; Published: 21 March 2018

check for updates

\begin{abstract}
We use origami to create a compact, scalable three-dimensional (3-D) biobattery stack that delivers on-demand energy to the portable biosensors. Folding allows a two-dimensional (2-D) paper sheet possessing predefined functional components to form nine 3-D microbial fuel cells (MFCs), and connect them serially within a small and single unit $(5.6 \mathrm{~cm} \times 5.6 \mathrm{~cm})$. We load the biocatalyst Pseudomonas aeruginosa PAO1 in predefined areas that form the MFCs, and freeze-dry them for long-term storage. The biobattery stack generates a maximum power and current of $20 \mu \mathrm{W}$ and $25 \mu \mathrm{A}$, respectively, via microbial metabolism when the freeze-dried cells are rehydrated with readily available wastewater. This work establishes an innovative strategy to revolutionize the fabrication, storage, operation, and application of paper-based MFCs, which could potentially make energy available even in resource-limited settings.
\end{abstract}

Keywords: microbial fuel cells; origami; paper battery stacks; on-demand power generation

\section{Introduction}

Microbial fuel cells (MFCs) are one of the most exciting new energy-scavenging technologies, especially for use in remote and resource-limited environments [1-3]. MFCs harvest bioelectricity from any biodegradable organic compounds (e.g., wastewater) via microbial electron transport chains. Existing MFCs have limited power generation, reducing their possible applications $[4,5]$. However, the technology remains attractive as a self-sustainable power supply, even in challenging environments. The MFCs have unique advantages over other energy-harvesting techniques, including (i) on-demand and rapid power generation without charging; (ii) low-cost materials and easy fabrication; and (iii) self-assembling and self-repairing bacterial features that make the MFCs (iv) self-sustainable and eco-friendly. Furthermore, the technique can be useful for powering underwater wireless sensor networks [6]. Many research groups have revolutionized the MFC technique and its applications by miniaturizing the device for powering standalone and portable electronics that require low energy consumption, but simple and fast energy production [7-12]. One of the excellent application examples of the miniaturized MFCs powers disposable point-of-care (POC) biosensors, demanding only tens of micro-power for a couple of minutes [13-15]. Recent paper-based miniaturized MFCs are attracting more attention as a power source because they fulfill the ASSURED biosensor criteria that the World Health Organization defined for diagnostic devices in developing countries: Affordable,

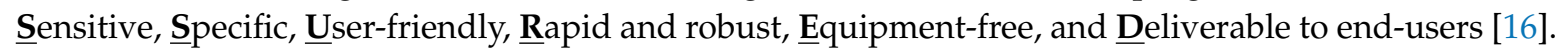
Paper MFCs can be readily incorporated in those ASSURED biosensors for easy system integration, offering low-cost, disposable, rapid, and simple power generation without external equipment [17-26]. The biocompatibility and fiber structure of paper induces the formation of a densely packed biofilm and generates high performance, as they provide a large surface area for bacterial attachments and a porous structure for the efficient mass transfer of ions, nutrients, and byproducts. Significant advances 
in technology allow us to add patterned conductive and hydrophilic characteristics to paper, increasing its suitability as a substrate for MFCs [27-29]. The added characteristics allow the effective harvesting of electrons from the MFCs. In addition, our recent ability to freeze-dry electricity-generating bacterial cells (or exoelectrogens) in paper allowed a long battery shelf life and the easy activation for a self-powered device in resource-limited settings [29].

The sufficient number of the bacterial cells can be stored intact without losing their electron-generating capacity until used, and be readily activated by various liquids available in any challenging area. Very recently, we demonstrated an MFC battery stack fabricated on a single sheet of paper that allowed on-demand activation with human saliva [29,30]. All of the functional layers for the fuel cell architecture were precisely designed in the paper sheet, and 16 MFC units were connected in a series to increase the power and output voltage. However, several practical challenges remain. First, the device $(16 \mathrm{~cm} \times 10 \mathrm{~cm})$ was too big to carry around. This is because the metallic wires and electrical switches had to be patterned and mounted, respectively, on the paper to connect the MFCs in series, taking up $18 \%$ of the device. The electrical switches were necessary, because individual MFC units must be disconnected until they reach the maximum performance level. Otherwise, a voltage reversal from the weakest unit will take place, reducing the overall battery performance [31]. Second, the anodic chamber volume was very limited, because of the other necessary components (i.e., membrane and cathode) that needed to be integrated into a single sheet of paper. Since the anodic chamber volume determines the actual surface area for the bacterial attachment, this limiting factor can substantially reduce the performance of the MFC [26,29].

In this work, we created a compact three-dimensional (3-D) battery stack through the origami technique, reducing the overall device size by about $20 \%(5.6 \mathrm{~cm} \times 5.6 \mathrm{~cm})$ and eliminating the limitation in controlling the anodic chamber volume (Figure 1a). A two-dimensional (2-D) sheet of paper was designed and patterned to have folding tabs on which holes (for cathodic reaction and sample injection, respectively), anodic chambers, an air cathode, and electrical wires were fabricated (Figure 1b,c). By folding the tabs, nine MFC units were configured and connected in series (Figure $1 \mathrm{~d}-\mathrm{g}$ ). The metallic wires were well designed and patterned on two designated folding tabs, which upon folding reduced the size compared to previous devices. The specific folding pattern created the series connection of the nine MFCs. Furthermore, folding and unfolding the device functioned as an electrical switch for the series connection. The multilayer configuration ensured that the anodic chamber was occupied throughout the entire device, and also increased the overall volume and surface area for the bacterial attachments. This innovative platform allowed us to combine multiple individual batteries into a single, stronger pocket-sized battery stack, making the batteries easier to transport; it also allowed us to explore designs that are not possible with rigid materials. Finally, simple batch-fabrication methods (i.e., printing, brushing, and spraying) were applicable for the mass production of the paper-based MFCs. Freeze-dried Pseudomonas aeruginosa PAO1 in the conductive and hydrophilic anodic chambers were rehydrated by using wastewater as an organic activation sample, and the nine MFCs connected in series generated a maximum output voltage of $2.3 \mathrm{~V}$ and power of $20 \mu \mathrm{W}$, which will be sufficient to operate actual low-power biosensing applications. This pocket-sized device holds considerable promise as an on-demand power source for use in remote and resource-limited environments. 

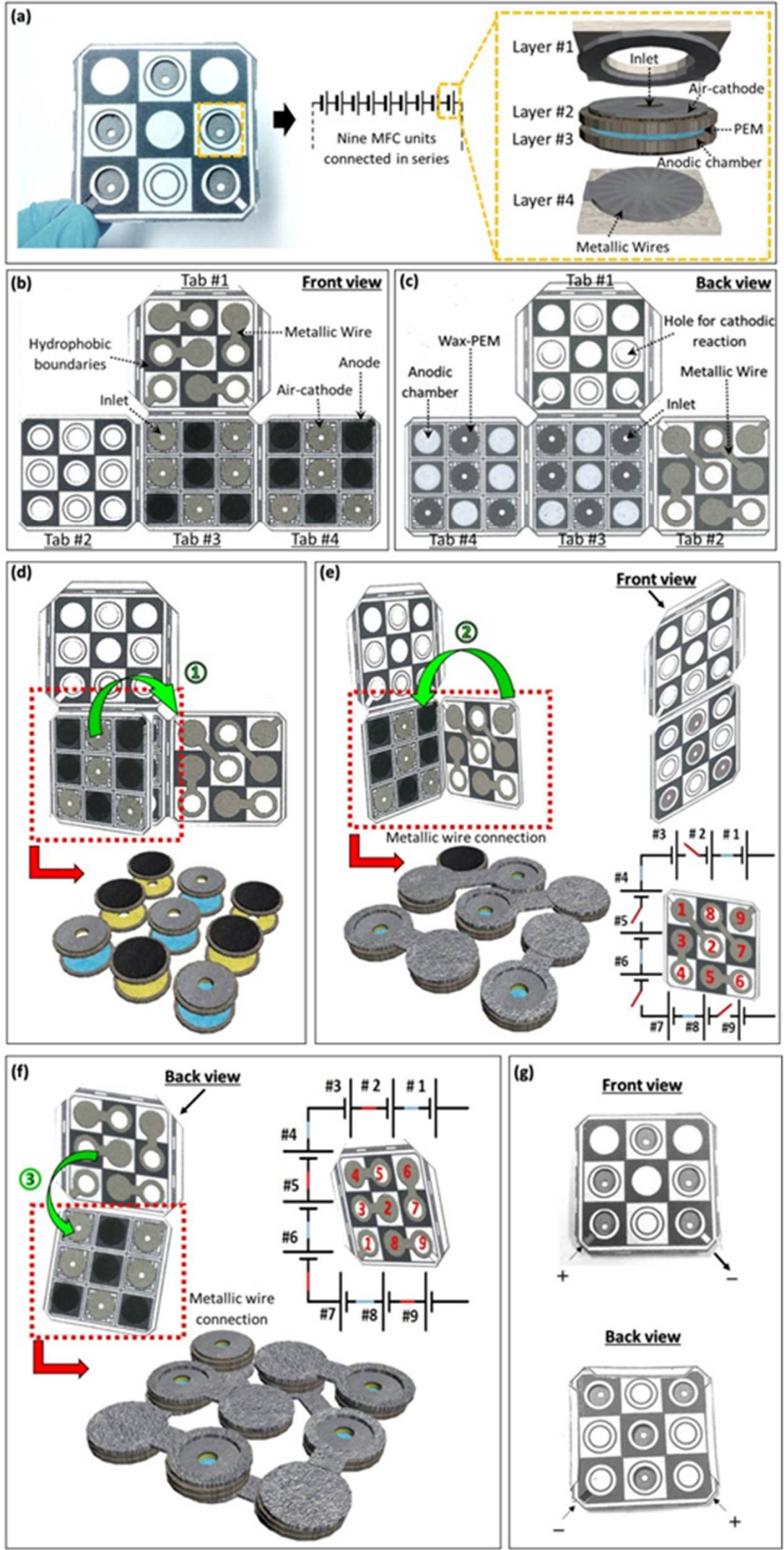

Figure 1. (a) An origami paper-based biobattery stack and schematic diagram of a cross-section of the single unit; (b) Front and (c) back view of the two-dimensional (2-D) sheet of paper before folding; (d-f) Folding processes for the three-dimensional (3-D) battery stack and its metallic wire configuration; (g) Front and back view of the folded battery stack. 


\section{Experimental Sections}

Materials: Poly(3,4-ethylened ioxythiophene):polystyrene sulfonate (PEDOT:PSS), $5 \mathrm{wt} \%$ Nafion solution, dimethyl sulfoxide (DMSO), 3-glycidoxypropy-trimethoxysilane (3-G) were purchased from Sigma-Aldrich. Activated carbon (AC) powders and a nickel conductive spray were obtained from Cabot Corporation (Boston, MA, USA) and MG Chemicals (Burlington, ON, Canada), respectively. Whatman 3MM chromatography papers (Philadelphia, PA, USA) were purchased from VWR. All materials and chemicals were used as received without further treatment.

Wax patterning on paper: MFC devices were fabricated using a wax printing technique. Specific device patterns were designed using AutoCAD software, and printed onto the chromatography paper using Xerox Phaser printer (ColorQube 8570 (Fairfield County, CT, USA)). Then, the printed paper was placed in an oven set at $150{ }^{\circ} \mathrm{C}$ for $30 \mathrm{~s}$, and the hydrophobic wax melted into the paper substrate, defining device boundaries, forming PEMs, and strengthening the paper while retaining its flexibility.

Hydrophilic and conductive anodic chambers in paper: A 30- $\mu \mathrm{L}$ mixture of $1 \mathrm{wt} \%$ PEDOT:PSS and $5 \mathrm{wt} \%$ DMSO was sprayed onto the 2-D paper through a patterned stencil to form anodic chambers and air-dried for $8 \mathrm{~h}$, which was repeated up to four times to reduce the sheet resistances of the anodes. To further increase their hydrophilicity, $20 \mu \mathrm{L}$ of $2 \mathrm{wt} \%$ 3-glycidoxypropy-trimethoxysilane was also sprayed to individual chamber regions and air dried.

Air cathodes on paper: AC-based air cathodes were formed on paper with a nickel spray, which provides better conductivity for the cathode. The detailed fabrication processes for the air cathode on paper were reported in our previous reports [24-26]. In short, $15 \mathrm{mg} \cdot \mathrm{cm}^{-2} \mathrm{AC}$ catalysts with a binder solution were brushed on the wax-based PEM, and subsequently air dried for $24 \mathrm{~h}$ (Figure S1). The binder solution was prepared with (i) $1200 \mu \mathrm{L}$ of $5 \mathrm{wt} \%$ Nafion solution; (ii) $150 \mu \mathrm{L}$ of deionized water; and (iii) $600 \mu \mathrm{L}$ of isopropanol into a beaker, followed by ultrasonication for $1 \mathrm{~min}$.

Metallic wires on paper: The thin-film plastic stencils for the metal deposition (1/16-inch acrylic sheets, McMaster-Carr (Aurora, OH, USA) were micromachined by laser cutting (Universal Laser System VLS 3.5). Nickel metallic wires were then sprayed onto the paper through the stencils.

Inoculum: Pseudomonas aeruginosa $\mathrm{PAO} 1$ were cultured from $-80^{\circ} \mathrm{C}$ from bacterial glycerol stock by inoculating $30 \mathrm{~mL}$ of LB medium with gentle shaking in the air for $24 \mathrm{~h}$ at $35^{\circ} \mathrm{C}$. The LB media consisted of $10.0 \mathrm{~g}$ tryptone, $5.0 \mathrm{~g}$ yeast extract, and $5.0 \mathrm{~g} \mathrm{NaCl}$ per liter. The culture was then centrifuged at $5000 \mathrm{rpm}$ for $5 \mathrm{~min}$ to remove the supernatant. The bacterial cells were re-suspended in a new medium, and preloaded in the anodic chambers.

Freeze-drying: After the MFCs were preloaded with bacterial cells, the device was placed in a freeze dryer (FreeZone Plus 2.5 Liter Cascade Benchtop Freeze Dry System, Labconco, MO, USA) and the drying operation was performed at a pressure of $0.06 \mathrm{~atm}$ for $24 \mathrm{~h}$ with freezing, sublimation, and desorption processes. During the processes, the chamber temperature dropped to $-25{ }^{\circ} \mathrm{C}$, and then progressively increased back to room temperature. The paper MFCs were not affected by the freeze-drying process.

Bacterial Fixation and SEM Imaging: The SEM image samples were taken from anodic chambers with bacteria. They were immediately fixed in $2 \%$ glutaraldehyde solution overnight at $4{ }^{\circ} \mathrm{C}$. Samples were then dehydrated by 5 -min serial transfers through $50 \%, 70 \%, 80 \%, 90 \%, 95 \%$, and $100 \%$ ethanol. Fixed samples were examined using a FESEM (field emission SEM) (Supra 55 VP, Zeiss (Jena, Germany)).

\section{Results and Discussion}

The MFC was based on a two-chambered device configuration consisting of an anode and an air cathode separated by a proton exchange membrane (PEM) (Figure 1a). The exoelectrogens were contained in the engineered conductive and hydrophilic anode chambers and freeze-dried until used. The introduction of wastewater through an inlet connected to the anodic chamber rehydrated the freeze-dried cells, activating their metabolism and producing electrons and protons. The electrons were transferred to the conductive paper fibers and moved to the external circuit while the protons 
were transported to the cathode through the PEM to maintain the electroneutrality of the system. At the air cathode exposed to the air through the large hole (Figure 1a,c), the protons were reduced with the oxygen, and electrons traveled from the anode.

\subsection{Conductive and Hydrophilic Anodic Chambers}

In order to hold the exoelectrogens in liquid and harvest electrons from the cells distributed by capillary action throughout the 3-D porous structure of paper, each paper fiber needs to be hydrophilic and conductive (Figure 2). Conducting polymers such as poly(3,4-ethylenedioxythiophene):poly(styrene sulfonate) (PEDOT:PSS) have been widely used to fabricate conducting papers, as they possess controllable electrical conductivity ranging from semiconductors to metals [32]. Many studies demonstrated that the conductivity of the PEDOT:PSS can be substantially improved by mixing it with other solvents such as dimethyl sulfoxide (DMSO) and ethylene glycol (EG) [27-29,33].

(a) Non-conductive paper chamber

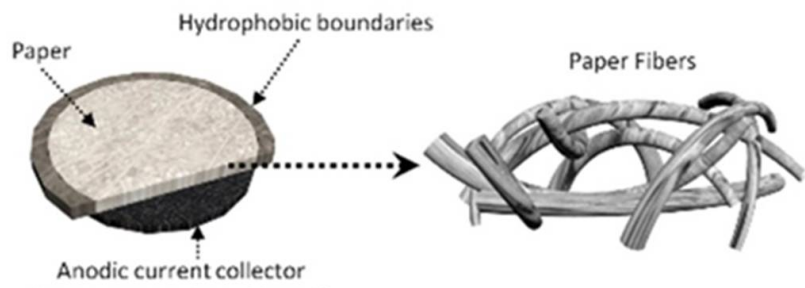

(screen-printed graphite ink)

(b) Conductive coating with DMSO-modified PEDOT:PSS

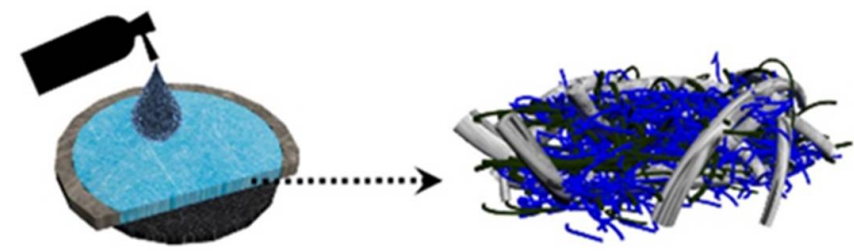

(c) Hydrophilic coating with 3.G

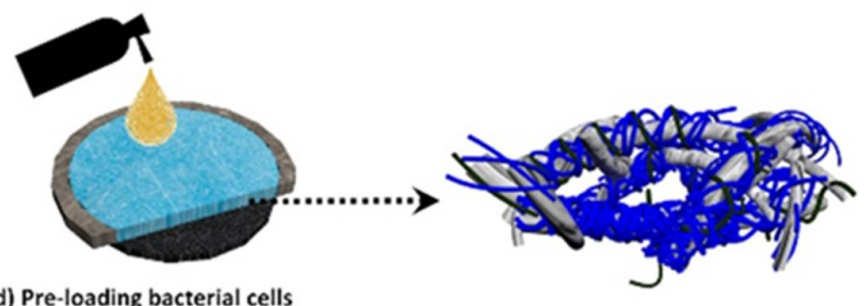

(d) Pre-loading bacterial cells

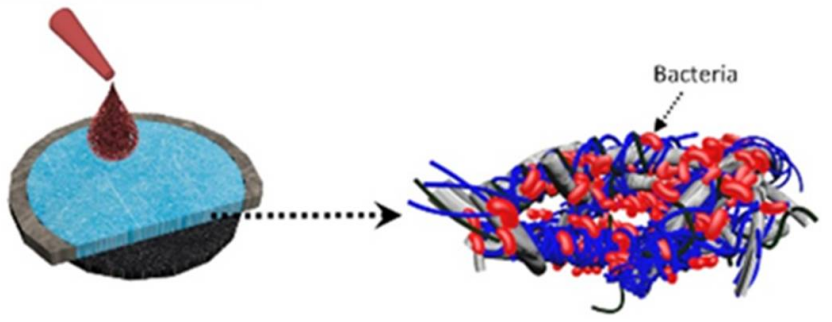

Figure 2. Schematic illustration of the fabrication steps for conductive and hydrophilic anodic chambers. (a) Defining Hydrophobic boundaries, (b) Conductive engineering the anodic reservoir, (c) Hydrophilic coating of the reservoir, and (d) pre-loading exoelectrogens.

Furthermore, its hydrophilicity can be enhanced by adding 3-glycidoxypropy-trimethoxysilane (3-G) [27-29]. Previously, 3-G/DMSO-modified PEDOT:PSS was used to define conductive and hydrophilic regions in the paper, which revolutionarily created a new, simple, and scalable fabrication 
method for making paper-based printed circuit boards [27]. Our group for the first time applied this technique to a paper-based MFC, gaining greatly improved performance from a conductive and hydrophilic anodic chamber [29,30,34]. In this work, a more batch-fabricable approach was proposed to simultaneously define nine anodic chambers on the 2-D non-conducting paper sheet (Figure 2a). The DMSO-modified PEDOT:PSS mixture (Figure 2b) and the 3-G solution (Figure 2c) were poured into a spray gun glass bottle, and sprayed onto the entire surface of the paper. The solution slowly but efficiently absorbed into the paper. We then could form conductive and hydrophilic anodic reservoirs without blocking any of the paper's pores (Figure 3a,b). This structure enabled conformal and densely packed biofilm formation (Figure $2 \mathrm{~d}, \mathrm{c})$. The sheet resistance $\left(\sim 350 \mathrm{ohm} \cdot \mathrm{sq}^{-1}\right)$ of the engineered anodic chamber was measured by using a four-point probe method, and did not significantly change even with repeated extensive mechanical deformations (up to 80 bending cycles) (Figure 4). This indicates that the conductive and hydrophilic chemical coating is stable and resilient on paper substrates.

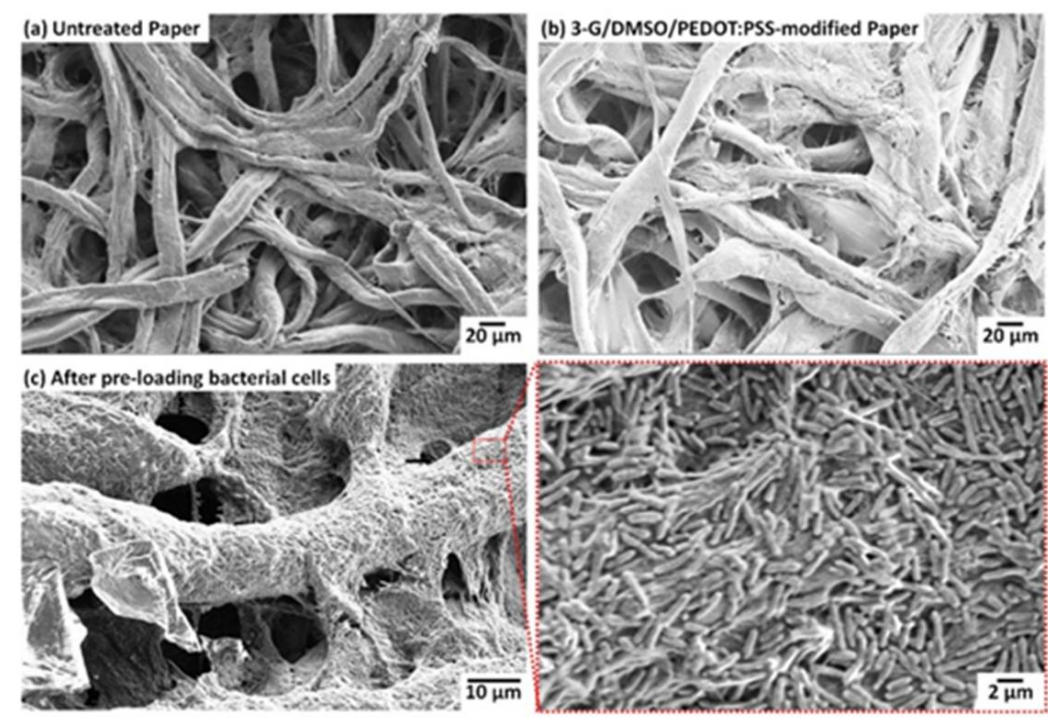

Figure 3. SEM (Scanning electron microscope) images of the anodic chamber. (a) Non-treated paper and 3-G/DMSO/PEDOT:PSS-treated paper (b) without and (c) with bacterial cells. 3-G: 3-glycidoxypropy-trimethoxysilane; DMSO: dimethyl sulfoxide; PEDOT:PSS: poly(3,4ethylenedioxythiophene):poly(styrene sulfonate).

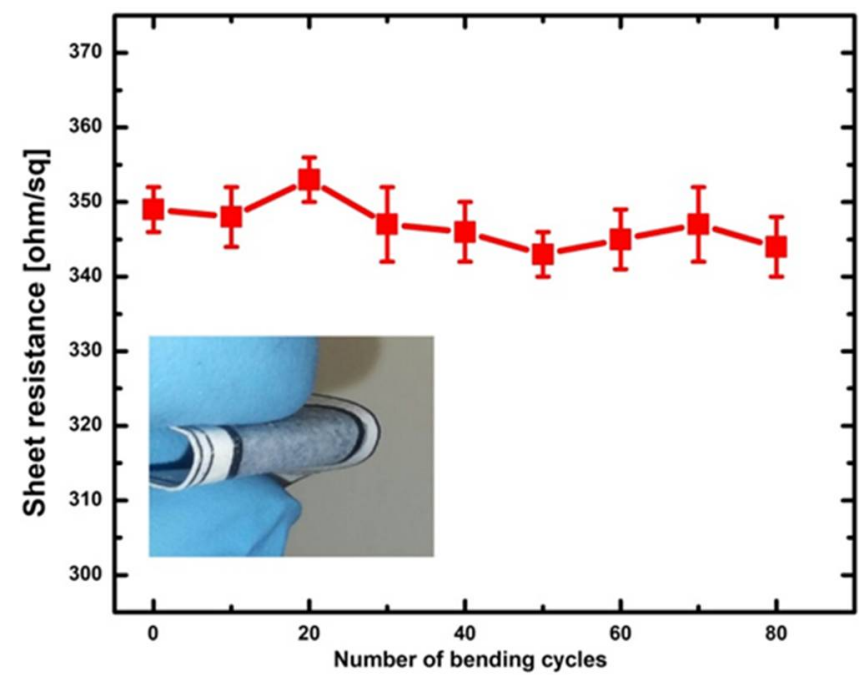

Figure 4. Sheet resistance of the anodic chamber vs. the number of bending cycles. 


\subsection{Freeze-Drying Bacterial Cells}

For on-demand power generation and a long shelf life for the biobattery, the exoelectrogens were preloaded and freeze-dried in the engineered anodic chambers (Figure 5). The preloaded exoelectrogens covered the conductive paper fibers three-dimensionally and conformally, forming densely packed biofilms (Figure $3 c$ and Figure $5 a$ ). Then, the cells were freeze-dried, keeping them intact through the freezing, sublimation, and desorption processes (Figure $5 b$ ). Freeze-drying has been widely used for the long-term preservation of bacterial cells [35,36]. Although not all bacterial strains survive the process, and further studies on exoelectrogens are required, freeze-drying allows the MFC technology to find more applicable and potentially realizable applications as a practical and accessible power supply in remote and resource-constrained environments. We previously demonstrated that the wild-type Pseudomonas aeruginosa PAO1 can be freeze-dried and rehydrated so that their metabolism generates power (Figure 5c) [29]. Furthermore, our recent literature survey indicates that $P$. aeruginosa can produce protecting proteins under oxidative stress such as freeze-drying (Figure 5b) [37,38], which will probably improve their survival rate during the process.
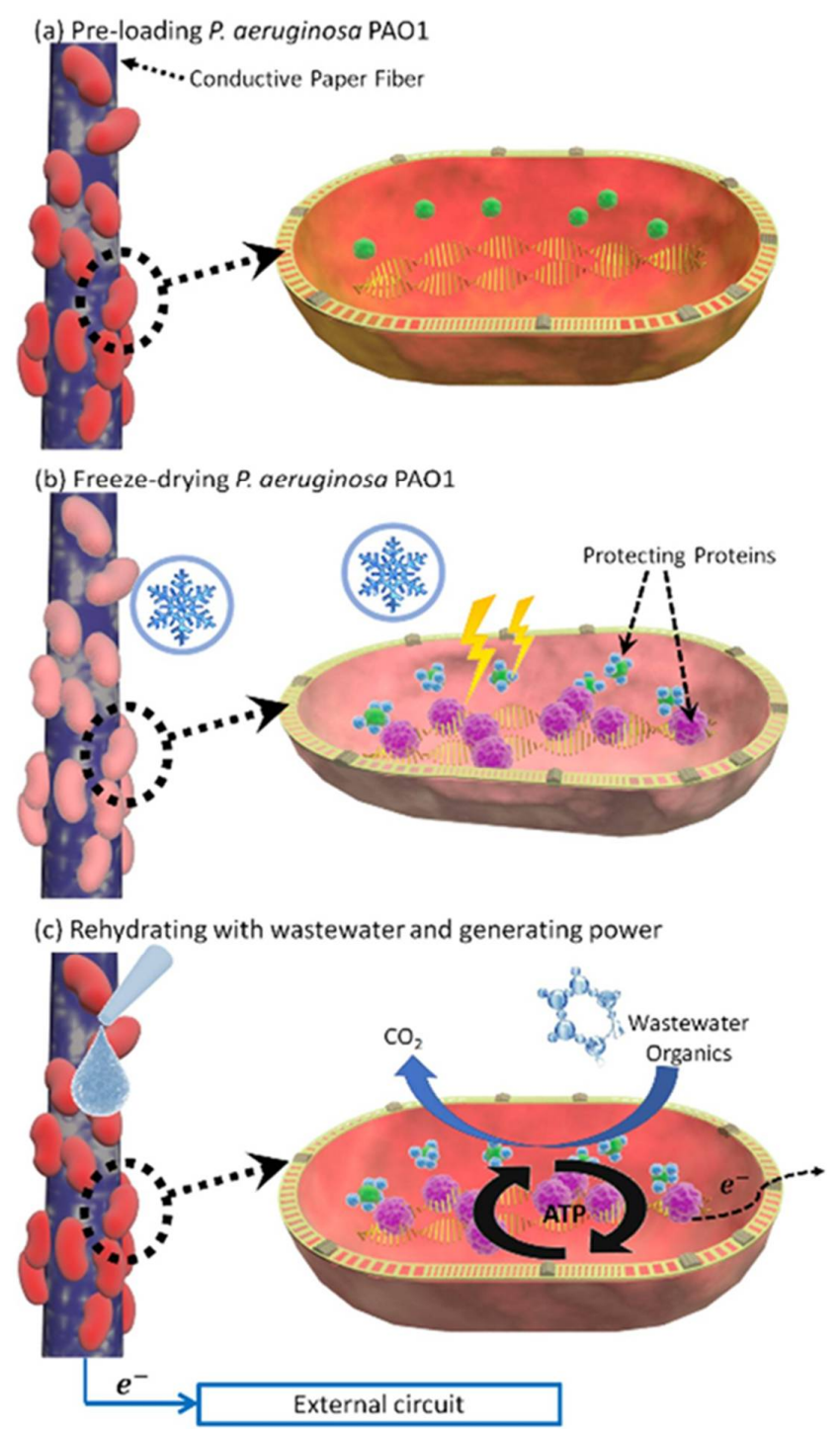

Figure 5. Schematic illustration of bacteria storage, their rehydration with wastewater, and their power generation. (a) Pre-loading bacterial cells in the anodic reservoir, (b) freeze-drying the device with the cells, and (c) rehydrating the cells for on-demand power generation. 
The rehydration of freeze-dried exoelectrogens is a critical step for on-demand power generation [39]. Among many factors affecting cell viability during rehydration, the media is important in restoring water to the dried cells. Our previous report showed that human saliva and bacterial media could activate the bacterial metabolism [29]. In this work, we tested organic wastes as a rehydration media, which are readily available in resource-limited areas. This result shows the potential of MFCs to harness energy from a wider range of soluble and renewable biomasses for practical applications. Further investigation of bacterial survival abilities after freeze-drying and during storage and rehydration will be our future work.

\subsection{Power Generation from a Single MFC Unit}

We first demonstrated fabrication and operation of a single MFC unit (Figure 6 and Figure S1). A 3-D MFC was created by folding a 2-D paper substrate with two functional folding tabs; one tab for an anodic bacterial respiration, and the other for a cathodic reaction. The anodic tab was engineered to have a conductive and hydrophilic feature with a carbon current collector, while the cathodic tab was composed of a wax-based PEM, an air-cathode catalyst layer, and a nickel current collector (Figure S2).
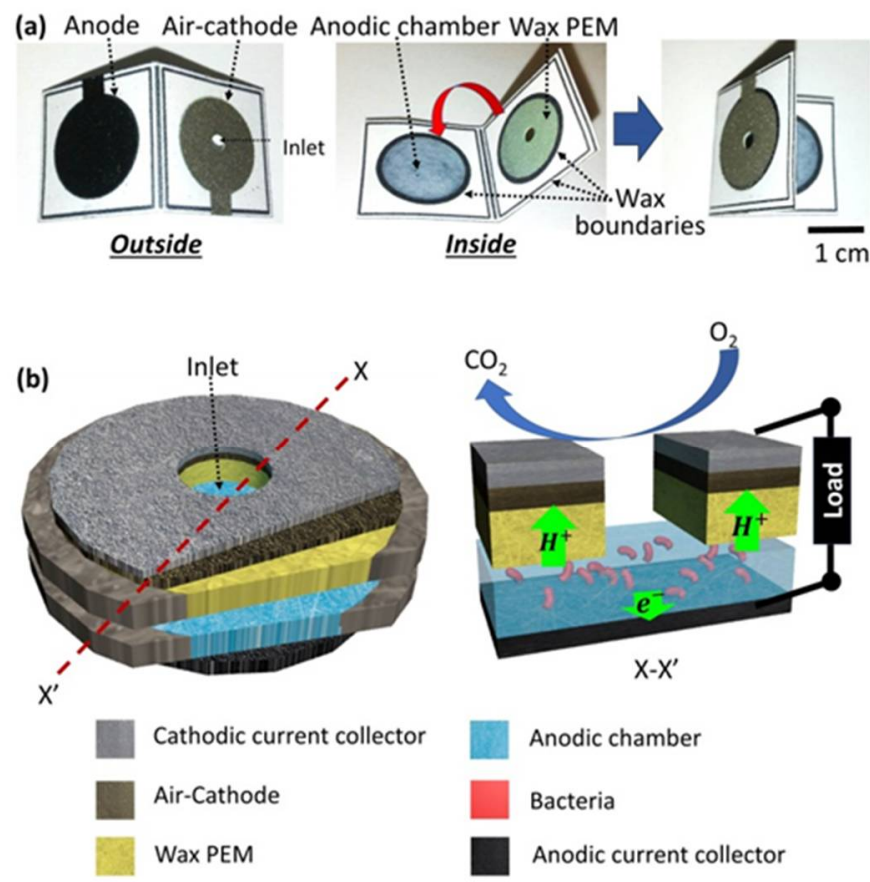

Figure 6. (a) Photos and (b) schematics of the single microbial fuel cell (MFC) unit.

Previously, many studies demonstrated that the wax-based PEM can work as an ion exchange membrane, separating the anodic part from the cathode while allowing protons to pass through $[18,19,25,26]$. The cathodic surface was exposed to the air for a maximized cathodic reaction, and a hole was made through the entire cathodic tab to allow the sample to be introduced to the anode after folding. First, we dropped various concentrations of the exoelectrogens in L-broth (LB) media in the engineered anodic chamber through the inlet on the cathode side, and measured the polarization/power curves with different external load resistances (Figure 7a). The optical density at $600 \mathrm{~nm}$ (OD600) was used to control the concentration. Given that the maximum power density of a fuel cell system is obtained when the external resistance is equal to the internal resistance of the system [40], Figure 7a shows that the internal resistances $(\sim 4 \mathrm{k} \Omega)$ of our MFCs were quite consistent with the increased bacterial concentrations, while their power and current densities were enhanced significantly. This indicates that the device was well fabricated, with no variation, and the folding procedure did not have any negative effects on the device performance. The maximum power and current densities 
of $1.23 \mu \mathrm{W} \cdot \mathrm{cm}^{-2}$ and $30 \mu \mathrm{A} \cdot \mathrm{cm}^{-2}$ were obtained, respectively, from the 1.0 OD600 concentration of the bacterial culture (Figure 7a). A higher concentration of culture than the 1.0 OD600 was too viscous to allow the solution to flow through the paper matrix, decreasing the MFC performance. Unless otherwise specified, the 1.0 OD600 concentration of the bacterial culture was used for the other experiments. The conductive and hydrophilic engineering of the paper with the 3-G/DMSO-modified PEDOT:PSS substantially improved the MFC performance, as the bacterial cells in media were easily distributed horizontally and vertically throughout the entire hydrophilic anode, and the cells were attached to the conductive paper fibers, harvesting electrons from the media (Figure 7b). This 3-D anodic scaffold extracted the collective electrons from all of the bacterial cells in the anodic chamber. The maximum power density from the engineered anodic chamber was $1.6 \mu \mathrm{W} \cdot \mathrm{cm}^{-2}$, which was about three times higher than that of the non-conducting paper MFC.
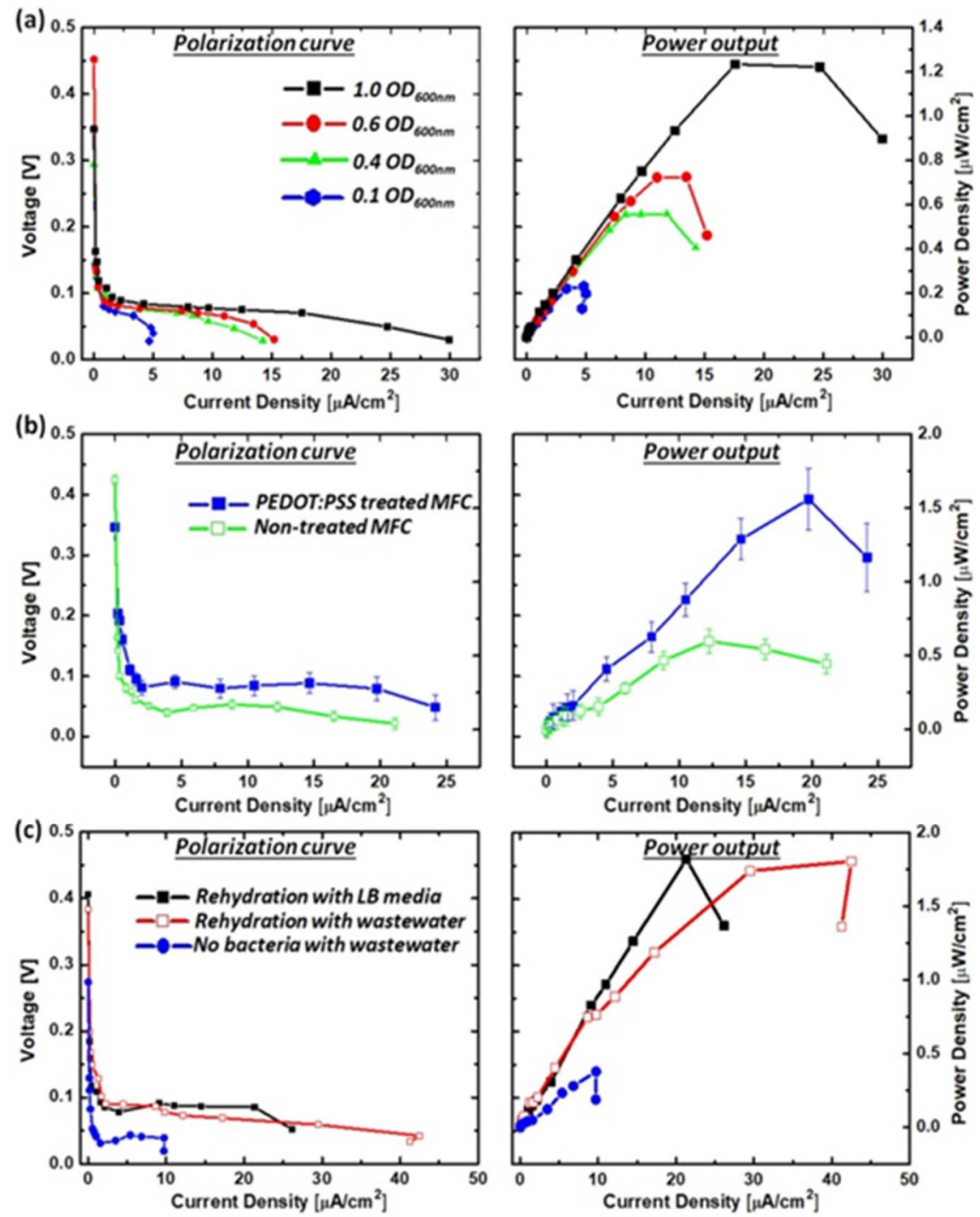

Figure 7. Polarization curves and power outputs measured from the single MFCs (a) with different concentrations of non-freeze-dried bacterial cells; (b) with 1.0 OD600 culture of non-freeze-dried cells in the anodic chamber with or without PEDOT:PSS treatment; and (c) with rehydrated freeze-dried cells (1.0 OD600 culture) in a different liquid. A control without bacterial cells was also prepared for comparison.

After we confirmed the optimal concentration of bacterial cells and engineered the anodic chamber for the high MFC performance, the bacterial cells were preloaded in the engineered anodic chamber 
and freeze-dried for storage. Then, the device with the cells was stored in our lab set at $22.8^{\circ} \mathrm{C}$ and $45 \%$ of relative humidity for three days (Figure S3a). For on-demand power generation, the freeze-dried bacterial cells were rehydrated with wastewater obtained from the Binghamton-Johnson City Joint Sewage Treatment Plant (Figure S3b).

The power density harvested from the wastewater was comparable to the LB media, and the current density was even higher than the media (Figure 7c). The control MFC without bacterial cells produced much smaller current and power outputs than the samples, indicating that the energy generation was mainly generated from the bacterial metabolism and their electron transfer reactions.

\subsection{Power Generation from a Nine-Cell MFC Stack}

The origami-inspired fabrication of the single MFC unit was extended to form a nine-MFC stack (Figure 1a). Basically, the MFCs were formed on two folding tabs consisting of the anodic and cathodic layers (Figure $1 \mathrm{~b}, \mathrm{c}$ ). Each folding tab was $5.6 \mathrm{~cm} \times 5.6 \mathrm{~cm}$, and included nine anodic or cathodic components (Figure S4). Two more folding tabs for the electrical series connections were added. By folding the tabs with a certain pattern along predefined creases, nine MFCs were created, and at the same time, they were all connected in series (Figure 1d-g).

We first preloaded the bacterial cells on each MFC anodic chamber and freeze-dried them. For easy and compact storage, the MFCs were folded until used. Since the cells were not activated and the external loads were not connected, the folding did not later affect the MFC operation. For on-demand power generation, we unfolded the device and introduced $25 \mu \mathrm{L}$ of wastewater as an activation liquid to each of the nine anodic chambers. We waited $5 \mathrm{~min}$ for the cells to be fully rehydrated and be ready for electron transfer. Then, we refolded the device, forming nine MFCs and connecting them in series.

Five repeated measurements with other MFC stacks had a relative standard deviation of less than $3.5 \%$. The open circuit voltage of the battery stack was $2.3 \mathrm{~V}$, and its maximum power and current were $20 \mu \mathrm{W}$ and $25 \mu \mathrm{A}$, respectively (Figure 8), which can be further improved by simply adding more MFCs and tabs within a small and single unit. This MFC stack platform is a great example of how easily paper can be folded and unfolded with the origami technique, and how multiple batteries can be combined in a compact manner.

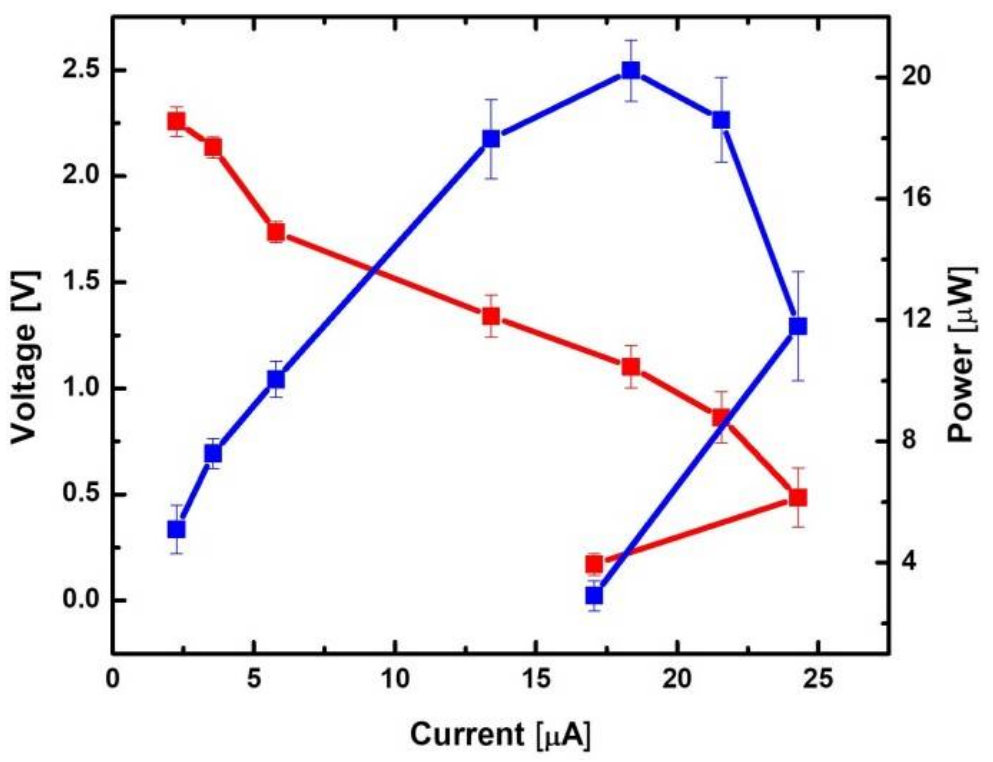

Figure 8. Polarization curves and output powers measured from the nine-MFC stack with wastewater activation liquid. 


\section{Conclusions}

We created an origami-inspired paper MFC stack, producing a maximum power and current of $20 \mu \mathrm{W}$ and $25 \mu \mathrm{A}$, respectively. Hydrophilic and conductive anodic chambers were formed in paper with 3-G/DMSO/PEDOT:PSS to improve bacterial biofilm formation and their metabolism, ultimately increasing the MFC performance. We also developed batch-fabrication processes for constructing multi-MFC units on a single sheet of paper. By folding, the 2-D paper formed 3-D MFCs, and connected them in series. Folding and unfolding acted as an electrical switch for the whole MFC stack operation. Freeze-drying was applied to store the bacterial cells, and rehydration generated on-demand power. In this work, we specifically used wastewater as a rehydration media to activate the freeze-dried bacterial cells and harvest bioelectricity from bacterial metabolism. The proposed origami technique revolutionized the fabrication, operation, and application of the paper-based MFCs, which can move this technique beyond the realm of conceptual research and advance its translational potential toward practical, real-world applications.

Supplementary Materials: The following are available online at http:/ / www.mdpi.com/2313-0105/4/2/14/s1, Figure S1: Fabrication processes, Figure S2: SEM images of the compartments, Figure S3: SEM images of bacteria, Figure S4: Device dimensions.

Acknowledgments: This work is supported by NSF (ECCS \#1503462, IOS \#1543944, \& ECCS \#1703394) and the SUNY Binghamton Research Foundation (SE-TAE).

Author Contributions: M.M. performed the experiments, analyzed the data and prepared the first draft; S.C. wrote the paper.

Conflicts of Interest: The authors declare no conflict of interest.

\section{References}

1. Chaturvedi, V.; Verma, P. Microbial fuel cell: A green approach for the utilization of waste for the generation of bioelectricity. Bioresour. Bioprocess. 2016, 3, 38. [CrossRef]

2. Li, S.; Cheng, C.; Thomas, A. Carbon-based microbial fuel cell electrodes: From conductive supports to active catalysts. Adv. Mater. 2017, 29, 1602547. [CrossRef] [PubMed]

3. Sun, M.; Zhai, L.-F.; Li, W.-W.; Yu, H.-Q. Harvest and utilization of chemical energy in wastes by microbial fuel cells. Chem. Soc. Rev. 2016, 45, 2847-2870. [CrossRef] [PubMed]

4. Babauta, J.; Renslow, R.; Lewandowski, Z.; Beyenal, H. Electrochemically active biofilms: Facts and fiction. A review. Biofouling 2013, 28, 789-812. [CrossRef] [PubMed]

5. Logan, B.E. Scaling up microbial fuel cells and other bioelectrochemical systems. Appl. Microbiol. Biotechnol. 2010, 85, 1665-1671. [CrossRef] [PubMed]

6. Shantaram, A.; Beyenal, H.; Raajan, R.; Veluchamy, A.; Lewandowski, Z. Wireless sensors powered by microbial fuel cells. Environ. Sci. Technol. 2005, 1, 5037-5042. [CrossRef]

7. Choi, S. Microscale microbial fuel cells: Advances and challenges. Biosens. Bioelectron. 2015, 69, 8-25. [CrossRef] [PubMed]

8. Qian, F.; Morse, D.E. Miniaturizing microbial fuel cells. Trends Biotechnol. 2011, 29, 62-69. [CrossRef] [PubMed]

9. Wang, H.; Bernarda, A.; Huang, C.; Lee, D.; Chang, J. Micro-sized microbial fuel cell: A mini-review. Bioresour. Technol. 2011, 102, 235-243. [CrossRef] [PubMed]

10. Jiang, H.; Ali, M.A.; Xu, Z.; Halverson, L.J.; Dong, L. Integrated microfluidic flow-through microbial fuel cells. Sci. Rep. 2017, 7, 41208. [CrossRef] [PubMed]

11. Siu, C.; Chiao, M. A microfabricated PDMS microbial fuel cell. J. Microelectromech. Syst. 2008, 17, $1329-1341$. [CrossRef]

12. Qian, F.; Baum, M.; Gu, Q.; Morse, D.E. A $1.5 \mu \mathrm{L}$ microbial fuel cell for on-chip bioelectricity generation. Lab Chip 2009, 9, 3076-3081. [CrossRef] [PubMed]

13. Fraiwan, A.; Lee, H.; Choi, S. A multi-Anode paper-based microbial fuel cell: A potential power source for disposable biosensors. IEEE Sens. J. 2014, 14, 3385-3390. [CrossRef] 
14. Thom, N.K.; Lewis, G.G.; DiTucci, M.J.; Phillips, S.T. Two general designs for fluidic batteries in paper-based microfluidic devices that provide predictable and tunable sources of power for on-chip assays. RSC Adv. 2013, 3, 6888-6895. [CrossRef]

15. Phillips, S.T.; Lewis, G.G. The expanding role of paper in point-of-care diagnostics. Expert Rev. Mol. Diagn. 2014, 14, 123-125. [CrossRef] [PubMed]

16. Mabey, D.; Peeling, R.W.; Ustianowski, A.; Perkins, M.D. Diagnostics for the developing world. Nat. Rev. Microbiol. 2004, 2, 231-240. [CrossRef] [PubMed]

17. Veerubhotla, R.; Das, D.; Pradhan, D. A flexible and disposable battery powered by bacteria using eyeliner coated paper electrodes. Biosens. Bioelectron. 2017, 94, 464-470. [CrossRef] [PubMed]

18. Lee, S.H.; Ban, J.Y.; Oh, C.-H.; Park, H.-K.; Choi, S. A solvent-free microbial-activated air cathode battery paper platform made with pencil-traced graphite electrodes. Sci. Rep. 2016, 6, 28588. [CrossRef] [PubMed]

19. Veerubhotla, R.; Bandopadhyay, A.; Das, D.; Chakraborty, S. Instant power generation from an air-breathing paper and pencil based bacterial bio-fuel cell. Lab Chip 2015, 15, 2580-2583. [CrossRef] [PubMed]

20. Zuo, K.; Liu, H.; Zhang, Q.; Liang, P.; Huang, X.; Vecitis, C.D. A single-use paper-shaped microbial fuel cell for rapid aqueous biosensing. ChemSusChem 2015, 8, 2035-2040. [CrossRef] [PubMed]

21. Winfield, J.; Chambers, L.D.; Rossiter, J.; Greenman, J.; Ieropoulos, I. Urine-activated origami microbial fuel cells to signal proof of life. J. Mater. Chem. A 2015, 3, 7058-7065. [CrossRef]

22. Fraiwan, A.; Mukherjee, S.; Sundermier, S.; Lee, H.-S.; Choi, S. A paper-based Microbial Fuel Cell: Instant battery for disposable diagnostic devices. Biosens. Bioelectron. 2013, 49, 410-414. [CrossRef] [PubMed]

23. Fraiwan, A.; Choi, S. Bacteria-Powered Battery on Paper. Phys. Chem. Chem. Phys. 2014, 16, 26288-26293. [CrossRef] [PubMed]

24. Lee, H.; Choi, S. An origami paper-based bacteria-powered battery. Nano Energy 2015, 15, 549-557. [CrossRef]

25. Fraiwan, A.; Kwan, L.; Choi, S. A Disposable Power Source in Resource-limited Environments: A Paper-based Biobattery Generating Electricity from Wastewater. Biosens. Bioelectron. 2016, 85, 190-197. [CrossRef] [PubMed]

26. Gao, Y.; Choi, S. Stepping Towards Self-powered Papertronics: Integrating Biobatteries into a Single Sheet of Paper. Adv. Mater. Technol. 2017, 2, 1600194. [CrossRef]

27. Hamedi, M.M.; Ainla, A.; Guder, F.; Christodouleas, D.C.; Fernandez-Abedul, M.; Whitesides, G.M. Integrating Electronics and Microfluidics on Paper. Adv. Mater. 2016, 28, 5054-5063. [CrossRef] [PubMed]

28. Hamedi, M.M.; Campbell, V.E.; Rothemund, P.; Guder, F.; Christodouleas, D.C.; Bloch, J.; Whitesides, G.M. Electrically Activated Paper Actuators. Adv. Funct. Mater. 2016, 26, 2446-2453. [CrossRef]

29. Mohammadifar, M.; Choi, S.; Papertronics, A. On-demand and Disposable Biobattery: Saliva-activated Electricity Generation from Lyophilized Exoelectrogens pre-inoculated on Paper. Adv. Mater. Technol. 2007. in print. [CrossRef]

30. Mohammadifar, M.; Zhang, K.; Choi, S. A saliva-powered paper biobattery for disposable biodevices. In Proceedings of the 2017 IEEE 30th International Conference on Micro Electro Mechanical Systems (MEMS), Las Vegas, NV, USA, 22-26 January 2017; pp. 121-124.

31. Oh, S.-E.; Logan, B.E. Voltage reversal during microbial fuel cell stack operation. J. Power Source 2007, 167, 11-17. [CrossRef]

32. Lee, C.; Lai, K.; Lin, C.; Li, C.; Ho, K.; Wu, C.; Lau, S.; He, H., Jr. A paper-based electrode using a graphene dot/PEDOT:PSS composite for flexible solar cells. Nano Energy 2017, 36, 260-267. [CrossRef]

33. Huang, J.; Kekuda, D.; Chu, C.; Ho, K. Electrochemical characterization of the solvent-enhanced conductivity of poly(3,4-ethylenedioxythiophene) and its application in polymer solar cells. J. Mater. Chem. 2009, 19, 3704-3712. [CrossRef]

34. Gao, Y.; Hassett, D.; Choi, S. Rapid Characterization of Bacterial Electrogenicity Using a Single-Sheet Paper-based Electrofluidic Array. Front. Bioeng. Biotechnol. 2017, 5, 44. [CrossRef] [PubMed]

35. Miyamoto-Shinohara, Y.; Sukenobe, J.; Imaizumi, T.; Nakahara, T. Survival of freeze-dried bacteria. J. Gen. Appl. Microbiol. 2008, 54, 9-24. [CrossRef]

36. Wenfeng, S.; Gooneratne, R.; Glithero, N.; Weld, R.J.; Pasco, N. Appraising freeze-drying for storage of bacteria and their ready access in a rapid toxicity assessment assay. Appl. Microbiol. Biotechnol. 2013, 97, 10189-10198. [CrossRef] [PubMed] 
37. Doberenz, S.; Eckweiler, D.; Reichert, O.; Jensen, V.; Bunk, B.; Sproer, C.; Kordes, A.; Frangipani, E.; Luong, K.; Korlach, J.S.; et al. Identification of a Pseudomonas aeruginosa PAO1 DNA Methyltransferase, Its Targets, and Physiological Roles. mBio 2017, 8, e02312-16. [CrossRef] [PubMed]

38. Whelan, D.R.; Hiscos, T.J.; Rood, J.I.; Bambery, K.R.; Mcnaughton, D.; Wood, B.R. Detection of an en masse and reversible B- to A-DNA conformational transition in prokaryotes in response to desiccation. J. R. Soc. Interface 2014, 11, 20140454. [CrossRef] [PubMed]

39. Costa, E.; Usall, J.; Teixido, N.; Garcia, N.; Vinas, I. Effect of protective agents, rehydration media and initial cell concentration on viability of Pantoea agglomerans strain CPA-2 subjected to freeze-drying. J. Appl. Microbiol. 2000, 89, 793-800. [CrossRef] [PubMed]

40. Fan, Y.; Sharbrough, E.; Liu, H. Quantification of the Internal Resistance Distribution of Microbial Fuel Cells. Environ. Sci. Technol. 2008, 42, 8101-8107. [CrossRef] [PubMed]

(C) 2018 by the authors. Licensee MDPI, Basel, Switzerland. This article is an open access article distributed under the terms and conditions of the Creative Commons Attribution (CC BY) license (http://creativecommons.org/licenses/by/4.0/). 